\title{
Superelliptic Broadband Transition Between Rectangular and Circular Waveguides
}

\author{
Larsen, Tove
}

Published in:

1st European Microwave Conference

Link to article, DOI:

10.1109/EUMA.1969.331859

Publication date:

1969

Document Version

Publisher's PDF, also known as Version of record

Link back to DTU Orbit

Citation (APA):

Larsen, T. (1969). Superelliptic Broadband Transition Between Rectangular and Circular Waveguides. In 1st European Microwave Conference (pp. 277-280). IEEE. https://doi.org/10.1109/EUMA.1969.331859

\section{General rights}

Copyright and moral rights for the publications made accessible in the public portal are retained by the authors and/or other copyright owners and it is a condition of accessing publications that users recognise and abide by the legal requirements associated with these rights.

- Users may download and print one copy of any publication from the public portal for the purpose of private study or research.

- You may not further distribute the material or use it for any profit-making activity or commercial gain

- You may freely distribute the URL identifying the publication in the public portal

If you believe that this document breaches copyright please contact us providing details, and we will remove access to the work immediately and investigate your claim 
SUPERELLIPTIC BROADBAND TRANSITION BETWEEN

RECTANGULAR AND CIRCULAR WAVEGUIDES

Tove Larsen

This paper is concerned with the construction of a short, gradual transition between the dominant modes of a rectangular and a circular waveguide as shown in Fig. I.

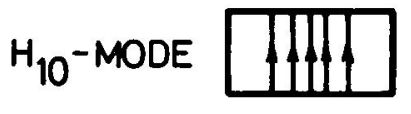

Fig. 1.
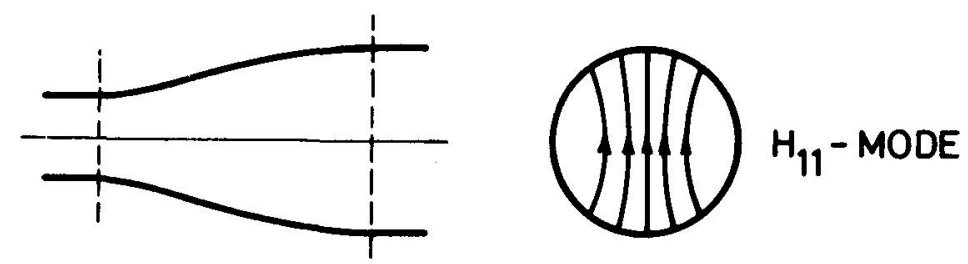

Such transitions are needed, for example, for coupling from rectangular waveguides to rotary vane attenuators or to rotary phase shifters, and they are required to have low reflections and to be broadbanded. These properties have been obtained by making the transitions rather long with a linear change of the cross section so that the transition becomes smooth. Another approach has been to make the transitions short and stepped in an optimum way, and cross sections like the ones shown in Fig. 2 have been suggested [1], [2], [3], and some of them used.

Fig. 2.

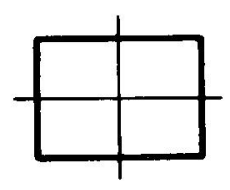

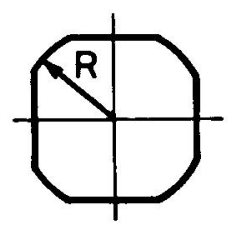
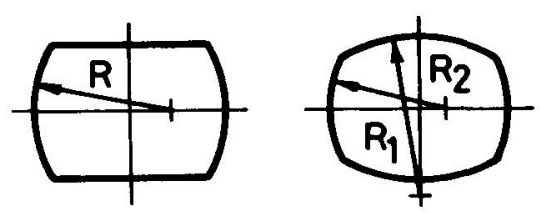

The purpose of the investigation reported here was to make a short and gradual transition by applying the superelliptic cross section, as shown in Fig. 3.

Fig. 3.

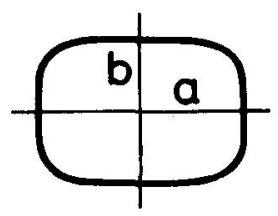

$$
\frac{x^{n}}{a^{n}}+\frac{y^{n}}{b^{n}}=1
$$

By means of three parameters (the exponent $n$ and the semiaxes $a$ and $b$ ) the shape of this curve may be changed continuously between any rectangle and circle.

Examples of various superellipses are shown in Fig. 4. When the exponent $n$ approaches infinity the rectangular form is obtained; for $n$ equal

Tove Larsen is with the Laboratory of Electromagnetic Theory, Technical University of Denmark, Lyngby, Denmark. 
to 10 the rectangle has rounded corners; for $n$ equal to 2 the superellipse becomes a normal ellipse, for $n=1$ a parallelogram and for $n$ less than one an asteroid. The concept may be extended to negative values of $n, t \infty o[4]$.

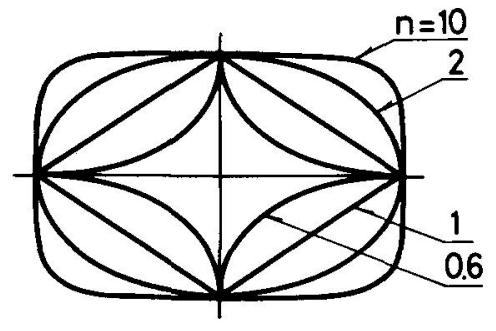

Fig. 4. Superellipses for various exponents.
The superellipse, which is a special type of Lamé curve, was introduced by Lamé in 1818 [5], and has since then occasionally been discussed by authors of geometrical textbooks [6]. However, it does not seem to have been applied for technical purposes until 1960, when Hein [7] suggested the use of a superellipse in the design of an oblong roundabout in the city of Stockholm, Sweden.

The possible application of superelliptic shapes in solving problems within electromagnetic theory is suggested. Theoretical work within electromagnetics has for a long time been confined to circular, elliptic, square and rectangular shapes because of the separability conditions. With the computer-aided solutions now available, it should be possible to investigate other shapes, and the superellipse formulation covers many shapes by a few parameters in a rather clear way.

The first simple attempt to apply the superellipses was the construction of the transition, to be described here, between rectangular and circular waveguides - a problem, the geometry of which seems to be suitable for application of these curves.

The basic criterion for the design of the transition is the same as was used for the stepped transitions [1], [2], namely to let every cross section have the same cut-off frequency in order to make the transition broadbanded. For this purpose, the cut-off frequencies of superelliptic waveguides were computed using a computer program based on the finite differences' method. This program was described by Pontoppidan [8] at this conference. The results are given in Fig. 5, which shows the cut-off wavelength of a superelliptic waveguide with the major axis equal to unity as a function of the minor axis - or the ratio between minor and major axes -

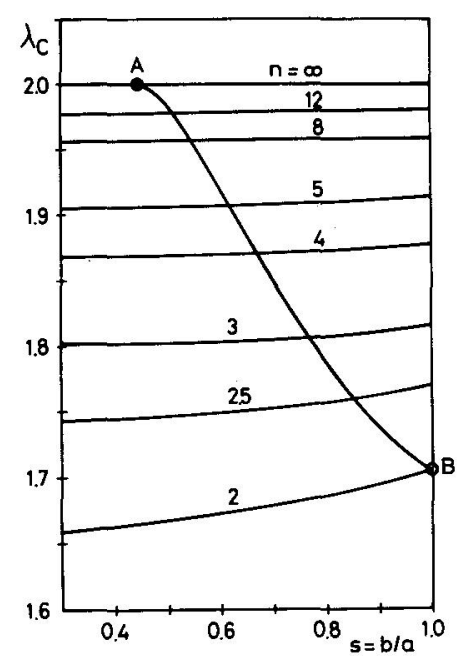

CUT OFF WAVELENGTH OF SUPERELLIPTIC

Fig. 5.
WAVEGUIDE WITH $2 a=1.0$ and with the exponent $n$ as a parmeter. The transition constructed is designed for transformation from the $\mathrm{X}$-band standard rectangular waveguide, WR 90 , to a circular waveguide. The rectangular waveguide corresponds to the point $A$ in Fig. 5 with the axis ratio $s$ equal to $0.44(=0.9 / 0.4)$ and an exponent $n$ equal to infinity. The circular waveguide corresponds to the point $B$ in Fig. 5 with the axis ratio $s$ equal to unity and the exponent 2 . In order to make a gradual transition, these two points should be connected with some smooth curve, which may be chosen in different ways. The one used here was chosen for mechanical reasons, and need not be the best fram an electrical point of view. It is 
chosen so that the cross sections have their largest dimension at the same angle from the major axis in order to be sure that all dimensions of the transition are increasing fram the rectangular to the circular end.

Next, the dimensions of the cross sections given by the points of the curve $A B$ - which is valid for cross sections with the major axis equal to unity - were multiplied by the ratio between the cut-off wavelength of the rectangular waveguide and the cut-off wavelengths read in Fig. 5 , thus determining the major axes so that every cross section has the same cut-off wavelength.

The next step was to decide the variation of the cross sections with the length coordinate of the transition instead of the axis ratio applied in Fig. 5. It was chosen to let the minor axis of the superellipses vary as a raised cosine, which gives the curves of Fig. 6 for the parameters of the superelliptic cross sections as a function of a normalized length coordinate. The actual length of the transition was quite arbitrarily chosen to be $3.5 \mathrm{~cm}$, which is almost the same as the length of the stepped transformers mentioned before [1], [2]. In Fig. 7 are show 36 of the cross
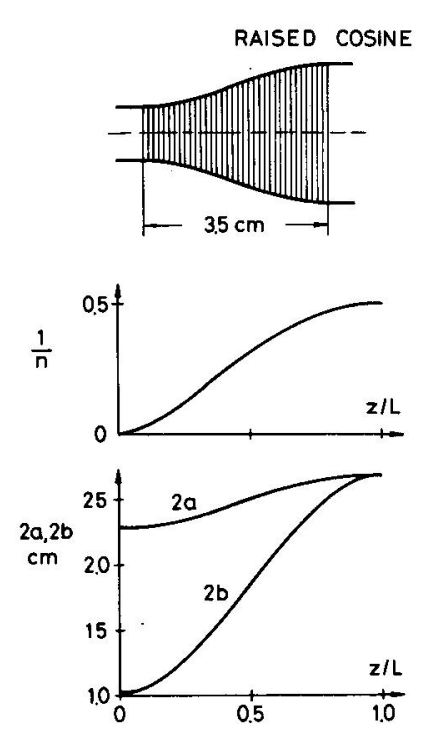

Fig. 6. Design curves for transition. sections plotted by the computer and used as workshop drawings. The actual transition was made by first making a mandrel partly by hand filing and afterwards using this in a stamping press to get the hollow form. The mandrel and the transition are shown in Fig. 8.

The measured standing-wave ratio curve of this short, gradual transition is compared with the corresponding curves for the two short stepped transitions [1], [2] in Fig. 9. This clearly shows that the stepped transitions have lower reflections than the gradual one. Possibly, this is due to a bad choice of the variation of the cross sections with the length

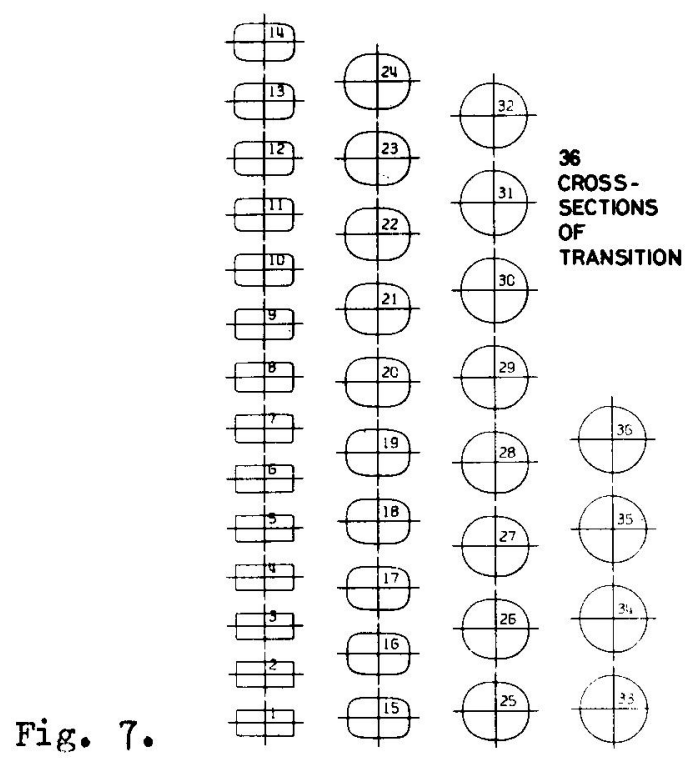

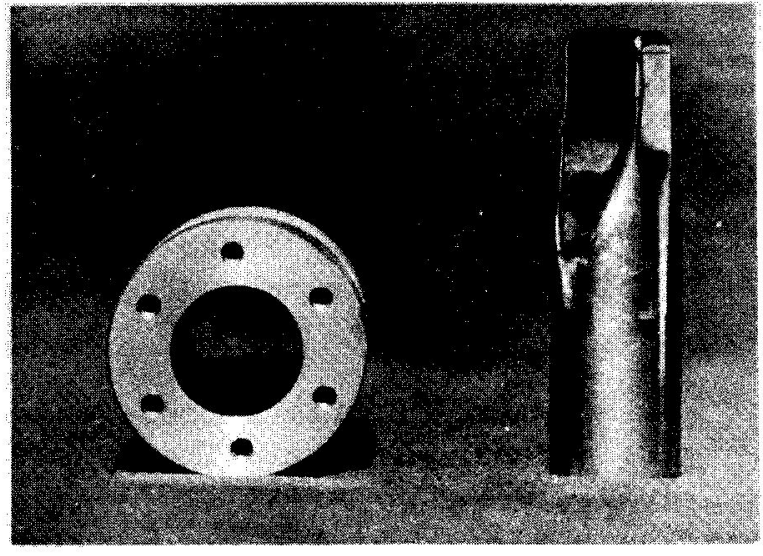

Fig. 8. Transition and mandrel. 


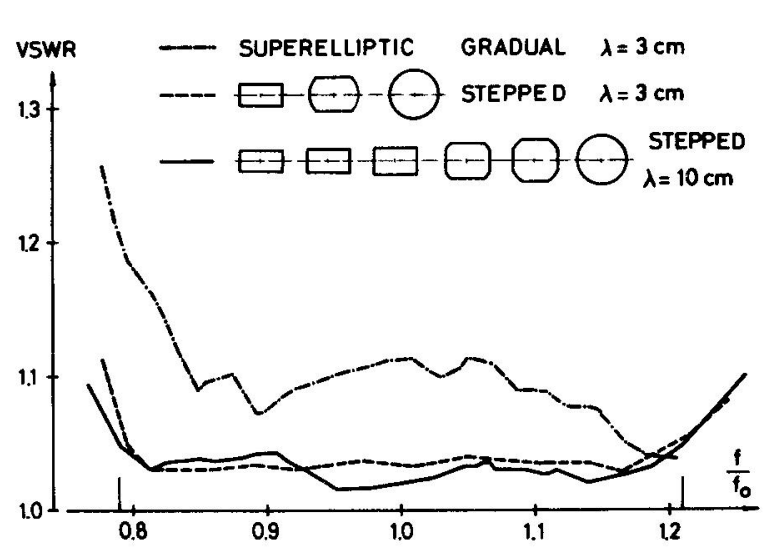

Fig. 9. coordinate of the gradual transition, and may be, to some degree, in mechanical inaccuracies. A better choice for the variation with length might be to apply same Tchebycheff polynomial design or to perform an optimization of Solymar's [9] expression for backward coupling into the main mode. This will be investigated more closely. Another problem will be to construct a transition between rectangular and elliptic waveguides along the same lines. The superelliptic waveguide cross sections might also become valuable in the design of overmoded systems, where it is of even greater importance that all changes are very gradual.

Literature

1. S. Stuchly and A. Kraszewski, "Wide-band rectangular to circular waveguide mode and impedance transformer". IEEE Trans. Microwave Theory and Techniques, Vol. MTT-13, pp. 379-380, May, 1965.

2. D. A. Bathker, "A st.epped mode transducer using homogeneous waveguides". IEEE Trans. Microwave Theory and Techniques, Vol. MTT-15, pp. 128-129, Februarj, 1967.

3. W. Schlosser and $G$. Weinhausen, "The calculation of normal modes in empty waveguides" (in German). Arch. Ellekt. Übertragung, Vol. 20, No. 10, pp. 557-62, October, 1966.

4. Tove Larsen, "Superelliptic and related coordinate systems". Report R 72. Laboratory of Electromagnetic Theory, Technical University of Denmark, 31 pp., August, 1969.

5. Lamé, "Examen des diff. méth, etc.". Paris 1818, $105 \mathrm{ff.}$

6. H. Wieleitner, "Special plane curves" (in German), pp. 356-362, Göschen'sche Verlagshandlung, 1908.

7. Martin Gardner, "The "superellipse": a curve that lies between the ellipse and the rectangle". Scientific American, Vol. 213, No. 3, pp. 222-232, September, 1965.

8. Knud Pontoppidan, "Numerical solution of waveguide problems using finite difference method". European Microwave Conference, London, September, 1969.

9. L. Solymar, "Spurious mode generation in non-uniform waveguide". IEEE Trans. Microwave Theory and Techniques, Vol. MTT-8, pp. 379-383, July, 1959. 